Gut, 1982, 23, 835-842

\title{
Polyps and cancer of the large bowel: a necropsy study in Liverpool
}

\author{
A R Williams, B A W BALASOORIYA, and D W DAY* \\ From the Department of Pathology, Royal Liverpool Hospital, Liverpool
}

SUMMARY In a prospective necropsy study of the large bowel in 365 cases, the commonest polyp identified was the hyperplastic (metaplastic) variety, of which $86.1 \%$ of the total were located in the rectum. The other main type of polyp found, and of much greater importance because of its malignant potential, was the neoplastic adenoma. These were present, either singly or multiply, in 73 of 198 male cases (36.9\%) and in 48 of 167 female cases $(28.7 \%)$. Their prevalence and their tendency to be multiple rose with increasing age in both sexes. Most adenomas had a tubular growth pattern and $88.8 \%$ of these were under $1 \mathrm{~cm}$ in diameter. There was a fairly even distribution of adenomas throughout the large bowel but a higher proportion of adenomas over 1 $\mathrm{cm}$ in diameter occurred in the caecum, sigmoid colon, and rectum than at other sites. In the whole series nine adenocarcinomas were present, two of which were arising in adenomas.

There is much clinical, experimental, and pathological evidence that the vast majority of carcinomas of the large bowel arise from adenomas, a process referred to as the adenoma-carcinoma sequence. ${ }^{1}$ The only obvious exception to this is in the case of cancer arising in long-standing ulcerative colitis, where the precursor dysplastic lesion is not a discrete polyp, but often affects a wide area of the bowel, which macroscopically may be flat or have a poorly circumscribed velvety or nodular appearance. $^{2}$

Whereas there is a mass of information relating to the incidence and distribution of colorectal carcinomas, much less is known about adenomas.

The aim of our prospective study was to determine the prevalence and distribution of adenomas in a consecutive study of cases at necropsy.

\section{Methods}

\section{MATERIAL}

The protocol followed was that drawn up jointly by the International Agency for Research on Cancer and the World Health Organisation for the study of large bowel pathology in necropsy series.

\footnotetext{
* Address for correspondence: Dr D. W Day, Department of Pathology, 5th Floor, Duncan Building, Royal Liverpool Hospital, Prescot Street, Liverpool L7 8XW.

Received for publication 8 February 1982
}

Over a period of approximately one year, the large bowel was examined in all cases coming to necropsy within 48 hours of death. This amounted to 365 specimens, 134 of which came from cases dying in hospital. The remaining 231 specimens were from necropsies ordered by a coroner where death had occurred outside hospital. An additional eight specimens were excluded, three where an antemortem diagnosis of large bowel cancer had been made, three where extensive autolysis precluded histological diagnosis, and two cases where the anorectal junction was not included in the specimen.

At necropsy, with the large bowel in situ, plastic clips were placed at the hepatic and splenic flexures and at the proximal and distal ends of the sigmoid colon (the point where the colon passes the inlet of the true pelvis, and the upper border of the $S 3$ segment of the os sacrum, respectively). A portion of the terminal ileum and the whole of the large bowel, including the anorectal junction, was then removed and opened along the antimesenteric border. After washing out the contents, the total length of the bowel and its subdivisions were measured. The size, site, and configuration of any mucosal polyp was recorded on a proforma. The bowel was then pinned out flat on a cork board and immersed in a tank of $10 \%$ buffered formalin for at least 24 hours, after which it was re-examined with the aid of an illuminating magnifying lens $(\times 2)$ by one of two observers (DWD and ARW). Any lesions detected were removed, processed, 
embedded in paraffin, sectioned, and stained with haematoxylin and eosin. In addition, in every case, a random block was taken from each anatomical segment and two blocks from the appendix when present (one longitudinal block from the distal end and a proximal transverse block).

Histological examination of the polyps separated them into two major groups, the hyperplastic or metaplastic polyp, and the neoplastic adenoma.

Hyperplastic polyps have a distinctive appearance comprising lengthened and dilated crypts lined by a serrated epithelium in which there are reduced numbers of goblet cells and an increased proportion of absorptive cells. ${ }^{34}$

Adenomas were categorised according to the World Health Organisation classification ${ }^{5}$ into tubular, tubulovillous, and villous types. Malignant change in an adenoma was considered to have occurred when neoplastic tissue was present deep to the muscularis mucosae. The only exception to this was in those cases where misplacement of benign epithelium below the mucosa (so-called pseudoinvasion) had taken place. ${ }^{6}$

\section{Results}

The vast majority of polyps on histological examination were of two types, either adenomatous or metaplastic (hyperplastic). The other polyps found (Table 1) were six submucosal lipomas (four of which were present in one case), a $0.5 \mathrm{~cm}$ diameter submucosal leiomyoma, and a similar sized carcinoid tumour, both of the latter tumours occurring in the rectum. In the 209 appendices examined two carcinoid tumours were present. Because of autolysis no histological diagnosis could be made on 19 polyps, all of these being less than 0.5 $\mathrm{cm}$ in diameter and occurring in specimens in which there were other diagnosable polyps.

\section{METAPLASTIC POLYPS}

In the whole series the presence of 168 metaplastic polyps was confirmed histologically. Grossly,

Table 1 Number and types of polyp in 365 necropsies

\begin{tabular}{lr}
\hline Type & (no.) \\
\hline Hyperplastic (metaplastic) polyp & 574 \\
Tubular adenoma & 233 \\
Tubulovillous adenoma & 8 \\
Villous adenoma & 1 \\
Lipoma & 6 \\
Leiomyoma & 1 \\
Carcinoid tumour & 1 \\
Polyps with no histological diagnosis & 19 \\
Total & 843 \\
\hline
\end{tabular}

however, there were far more of this type of polyp than adenomas (Table 1). Hyperplastic polyps usually have a characteristic macroscopic appearance, being smooth-surfaced, round or oval, sessile elevations often present on a mucosal fold and the same colour as the surrounding mucosa. They are mostly small, rarely being larger than 5 $\mathrm{mm}$ in diameter. They predominate in the rectum and are often multiple.

In individual cases, when multiple polyps with this gross appearance were present in the rectum, only some were examined histologically. Histology was done on single rectal lesions, where there was any doubt about the nature of a polyp from the macroscopic features, or in the occasional instance when the polyp was greater than $0.5 \mathrm{~cm}$ in diameter, although appearing grossly typical. If occurring at any other site, even though they appeared to be macroscopically typical, histology was carried out and in all these instances the characteristic appearances of a metaplastic polyp were present.

The prevalence of metaplastic polyps (Table 2) increased gradually with age in males with a slight decrease in the over 75 year age group. In females, where the prevalence was lower, the same trend was apparent apart from the 65-74 year age group.

Metaplastic polyps were slightly more frequent in cases with adenomas than those without. Thus they were present in $43.8 \%$ of the male cases and $31.2 \%$ of the female cases in the former group, compared with $38.4 \%$ of male cases and $26.1 \%$ of female cases in the group without adenomas.

The distribution of metaplastic polyps is shown in Table 3, which shows the marked propensity of this type of polyp to occur in the rectum.

\section{ADENOMAS}

In the 365 cases studied a total of 242 adenomas were detected, of which 233 were classified as tubular, eight as tubulovillous, and one as villous (Table 1). One or more adenomas were present in 73 of 198 male cases (multiple in 36) a prevalence of $36.9 \%$, and in 48 of 167 females (multiple in 22), a prevalence of $28.7 \%$. In both sexes the prevalence increased with increasing age, with higher rates in males at all ages (Table 2). No adenomas were found in the 19 cases (13 male and six female) where the age was below 35 years. In Fig. 1 the cumulative percentage of adenomas is charted for three different age groups, demonstrating a consistent increase in multiple adenomas with increasing age, so that, for example, almost $10 \%$ of cases from people over the age of 75 years had three or more adenomas compared with $2.4 \%$ under the age of 55 years.

In the whole series the mean size of the tubular 
Table 2 Prevalence of adenomas and hyperplastic polyps by age and sex

\begin{tabular}{|c|c|c|c|c|c|}
\hline $\begin{array}{l}\text { Age group } \\
(y r)\end{array}$ & $\begin{array}{l}\text { Intestines } \\
\text { examined }\end{array}$ & $\begin{array}{l}\text { Intestines } \\
\text { with adenomas }\end{array}$ & $\begin{array}{l}\text { Prevalence } \\
\text { (\%) }\end{array}$ & $\begin{array}{l}\text { Intestines with } \\
\text { hyperplastic } \\
\text { polyps }\end{array}$ & $\begin{array}{l}\text { Prevalence } \\
\text { (\%) }\end{array}$ \\
\hline \multicolumn{6}{|l|}{ Males } \\
\hline$<54$ & 55 & 11 & $20 \cdot 0$ & 21 & $38 \cdot 2$ \\
\hline $55-64$ & 44 & 15 & $34 \cdot 1$ & 19 & $43 \cdot 2$ \\
\hline $65-74$ & 57 & 25 & 43.9 & 26 & $45 \cdot 6$ \\
\hline $75+$ & 42 & 22 & $52 \cdot 4$ & 14 & $33 \cdot 3$ \\
\hline Total & 198 & 73 & $36 \cdot 9$ & 80 & $40 \cdot 4$ \\
\hline \multicolumn{6}{|l|}{ Females } \\
\hline$<54$ & 27 & 4 & $14 \cdot 8$ & 7 & 25.9 \\
\hline $55-64$ & 25 & 5 & $20 \cdot 0$ & 10 & $40 \cdot 0$ \\
\hline $65-74$ & 51 & 18 & $35 \cdot 3$ & 7 & $13 \cdot 7$ \\
\hline $75+$ & 64 & 21 & $32 \cdot 8$ & 22 & 34.4 \\
\hline Total & 167 & 48 & $28 \cdot 7$ & 46 & $27 \cdot 5$ \\
\hline
\end{tabular}

adenomas was $5.6 \mathrm{~mm}$ with $88.8 \%$ of them being under $1 \mathrm{~cm}$ in diameter. The mean size of the tubulovillous adenomas was $9.7 \mathrm{~mm}$ and the single villous adenoma was a $6 \mathrm{~cm}$ diameter sessile lesion in the caecum. There was no clear relationship between increases in size of adenomas with age in either cases with single or with more than one adenoma, although an increasing proportion of adenomas were $1 \mathrm{~cm}$ in diameter or larger in older age groups (Table 4).

The distribution of adenomas in the large bowel is illustrated in Fig. 2 where the numbers of adenomas observed in each of the anatomical segments is compared with the numbers expected if their distribution were uniform. The latter figures were obtained by calculating the mean length of each segment, its percentage of the mean total length of the bowel and, from this, the proportionate number of adenomas which would occur in that segment assuming an even distribution. There was a fairly good correlation between the observed and expected figures.

An alternative way of looking at distribution was to determine for each adenoma its distance along the bowel expressed as a percentage (the caecal pole being $0 \%$ and the anorectal junction $100 \%$ ). This showed (Fig. 3) that, when all adenomas were

Table 3 Distribution of metaplastic polyps in large bowel

\begin{tabular}{lcc}
\hline & Number & Proportion (\%) \\
\hline Caecum & 7 & $1 \cdot 2$ \\
Ascending colon & 14 & $2 \cdot 4$ \\
Transverse colon & 13 & $2 \cdot 3$ \\
Descending colon & 17 & $3 \cdot 0$ \\
Sigmoid colon & 29 & $5 \cdot 0$ \\
Rectum & 494 & $86 \cdot 1$ \\
Total & 574 & $100 \cdot 0$ \\
\hline
\end{tabular}

included, the distribution was more even than when cases were considered where only a single adenoma was present, when approximately half the total occurred in the first $10 \%$ and last $20 \%$ of the bowel.

Table 5 shows the distribution of adenomas of three different size groupings. There was a tendency for a higher proportion of adenomas over $1 \mathrm{~cm}$ in diameter to occur in the caecum, sigmoid colon, and rectum.

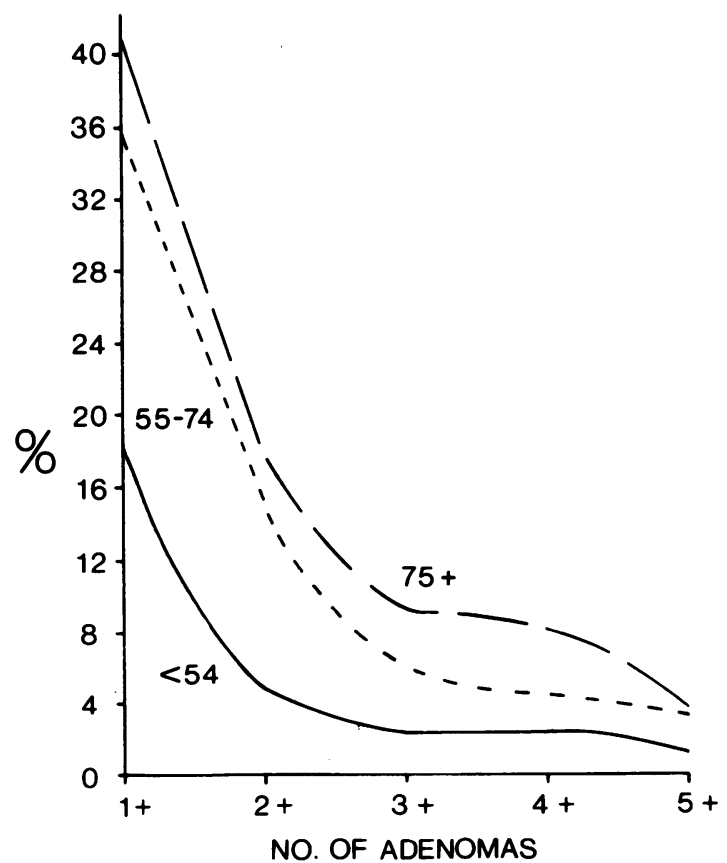

Fig. 1 Cumulative percentage of adenomas in three different age groups. 
Table 4 Adenoma sizes at different ages

\begin{tabular}{|c|c|c|c|c|c|}
\hline \multirow[b]{2}{*}{$\begin{array}{l}\text { Age group } \\
\text { (yr) }\end{array}$} & \multirow{2}{*}{$\begin{array}{l}\text { Total } \\
\text { number of } \\
\text { adenomas }\end{array}$} & \multicolumn{3}{|c|}{ Size $(\mathrm{mm})$} & \multirow{2}{*}{$\begin{array}{l}\text { Mean } \\
\text { diameter } \\
\text { of } \\
\text { adenomas } \\
(\mathrm{mm})\end{array}$} \\
\hline & & $\begin{array}{l}0-4 \\
(\%)\end{array}$ & $\begin{array}{l}5-9 \\
(\%)\end{array}$ & $\begin{array}{l}10+ \\
(\%)\end{array}$ & \\
\hline$<54$ & 22 & $63 \cdot 6$ & $31 \cdot 8$ & $4 \cdot 6$ & $4 \cdot 8$ \\
\hline $55-64$ & 37 & $35 \cdot 1$ & $54 \cdot 1$ & $10 \cdot 8$ & $7 \cdot 1$ \\
\hline $65-74$ & 93 & $38 \cdot 7$ & $48 \cdot 4$ & 12.9 & $5 \cdot 6$ \\
\hline $75+$ & 90 & $44 \cdot 4$ & 40.0 & $15 \cdot 6$ & $6 \cdot 1$ \\
\hline
\end{tabular}

The distribution of adenomas throughout the bowel in different age groups did not vary.

There was no significant difference in the prevalence of adenomas in hospital cases compared with those cases where death had occurred outside hospital. In fact, the prevalence was slightly higher in both males and females in the latter group.

All but one of the adenomas in the caecum were sessile but the proportion that were pedunculated increased in each segment distally to reach a peak in the sigmoid colon where three-quarters had a stalk (Table 6).

Pseudo-invasion was seen in a $2 \mathrm{~cm}$ diameter pedunculated tubulovillous adenoma in the transverse colon and in a $0.7 \mathrm{~cm}$ diameter pedunculated tubular adenoma in the sigmoid colon.

\section{CARCINOMA}

Adenocarcinomas were found in eight cases, in one of which there were two tumours. Two of the carcinomas were arising in adenomas. Details of these cases are given in Table 7.

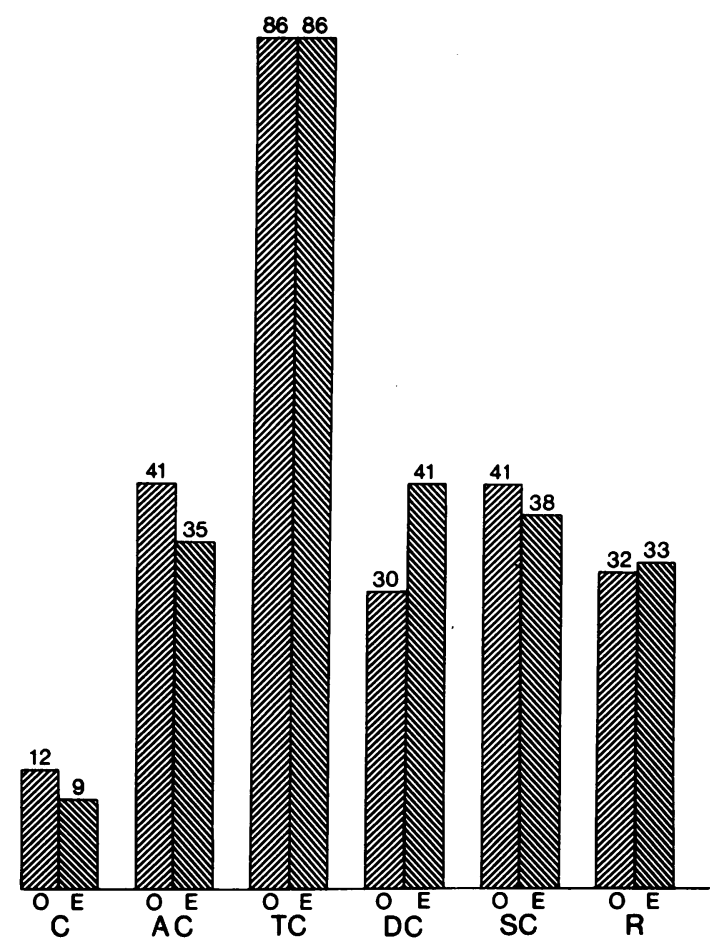

Fig. 2 Observed against expected numbers of adenomas by site. (C: caecum. AC: ascending colon. TC: transverse colon. DC: descending colon. SC: sigmoid colon. R: rectum.)

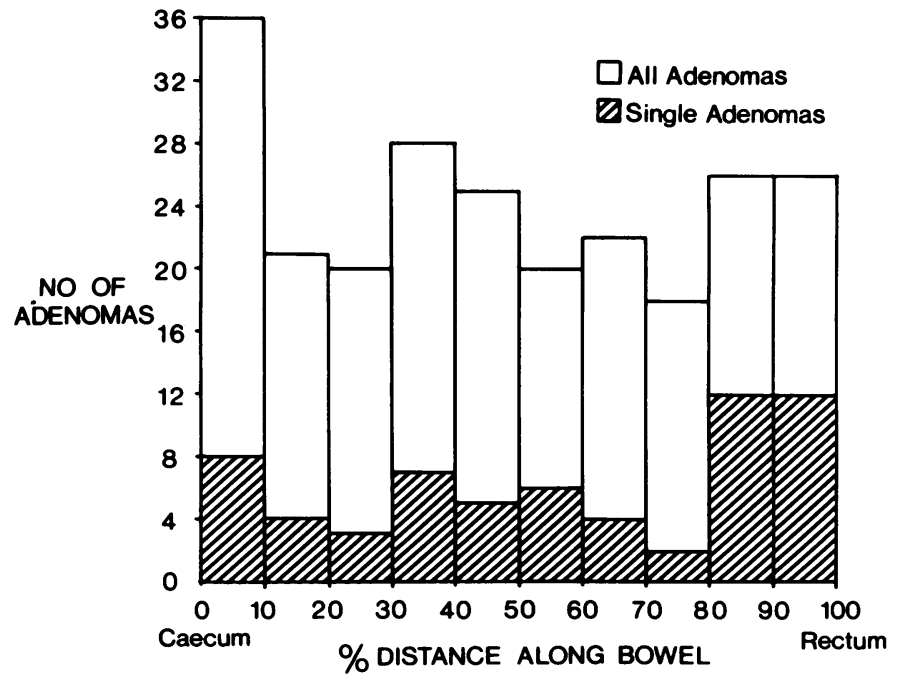

Fig. 3 Distribution of adenomas according to percentage distance along bowel wall. 
Table 5 Adenomas by size and location

\begin{tabular}{|c|c|c|c|c|c|c|c|c|}
\hline & \multirow{2}{*}{\multicolumn{2}{|c|}{ Total }} & \multicolumn{6}{|c|}{ Size (mm) } \\
\hline & & & \multicolumn{2}{|l|}{$<5$} & \multicolumn{2}{|l|}{$5-9$} & \multicolumn{2}{|l|}{$10+$} \\
\hline & no. & $\%$ & no. & $\%$ & no. & $\%$ & no. & $\%$ \\
\hline Caecum & 12 & 100 & 4 & $33 \cdot 3$ & 5 & $41 \cdot 7$ & 3 & $25 \cdot 0$ \\
\hline Ascending colon & 41 & 100 & 18 & 43.9 & 20 & $48 \cdot 8$ & 3 & $7 \cdot 3$ \\
\hline Transverse colon & 86 & 100 & 41 & $47 \cdot 7$ & 36 & $41 \cdot 8$ & 9 & $10 \cdot 5$ \\
\hline Descending colon & 30 & 100 & 10 & $33 \cdot 3$ & 17 & $56 \cdot 7$ & 3 & $10 \cdot 0$ \\
\hline Sigmoid colon & 41 & 100 & 17 & $41 \cdot 5$ & 16 & $39 \cdot 0$ & 8 & $19 \cdot 5$ \\
\hline Rectum & 32 & 100 & 13 & $40 \cdot 6$ & 14 & $43 \cdot 8$ & 5 & $15 \cdot 6$ \\
\hline Total & 242 & $(100)$ & 103 & $(42 \cdot 6)$ & 108 & $(44 \cdot 6)$ & 31 & $(12 \cdot 8)$ \\
\hline
\end{tabular}

Table 6 Pedunculated and sessile adenomas by location

\begin{tabular}{lcc}
\hline & Pedunculated & Sessile \\
\hline Caecum & 1 & 11 \\
Ascending colon & 18 & 23 \\
Transverse colon & 46 & 40 \\
Descending colon & 20 & 10 \\
Sigmoid colon & 31 & 10 \\
Rectum & 19 & 13 \\
\hline
\end{tabular}

\section{Discussion}

Hyperplastic polyps were the commonest type of lesion present in this necropsy survey and occurred predominantly in the rectum. Hyperplastic polyps were slightly more common in those cases with coexistent adenomas than those without, but this could be explained by differences in age distribution of the two groups. Although there is some

Table 7 Cases of carcinoma

\begin{tabular}{|c|c|c|c|c|c|}
\hline Case & $\begin{array}{l}\text { Age } \\
\text { and } \\
\text { sex }\end{array}$ & Size $(\mathrm{cm})$, site, Dukes's stage & $\begin{array}{l}\text { Associated adenomas } \\
(\mathrm{cm})\end{array}$ & $\begin{array}{l}\text { Death in } \\
\text { hospital }(H) \\
\text { or } \\
\text { outside }(O)\end{array}$ & Cause of death \\
\hline 1 & $72 \mathrm{M}$ & $\begin{array}{l}1 \cdot 0 \text {, pedunculated tubulovillous adenoma with } \\
\text { malignant change. } \\
\text { Sigmoid colon. A }\end{array}$ & $\begin{array}{l}1 \text { tubular adenoma } \\
0.4 \text {. Transverse colon }\end{array}$ & $\mathbf{H}$ & $\begin{array}{l}\text { Bronchopneumonia } \\
\text { (following resection of } \\
\text { gastric adenocarcinoma) }\end{array}$ \\
\hline 2 & $75 \mathrm{M}$ & $\begin{array}{l}5.0, \text { well-differentiated adenocarcinoma. } \\
\text { Ascending colon. B }\end{array}$ & $\begin{array}{l}4 \text { tubular adenomas } \\
\text { (1) } 0 \cdot 6 \text {. Ascending colon } \\
\text { (2) } 0 \cdot 4 \text {. Rectum } \\
\text { (3) } 0 \cdot 4 \text {. Rectum } \\
\text { (4) } 0 \cdot 8 \text {. Rectum }\end{array}$ & $\mathbf{O}$ & Myocardial infarct \\
\hline 3 & $76 \mathrm{M}$ & $\begin{array}{l}2 \cdot 3 \text {, polypoid mucin-secreting adenocarcinoma. } \\
\text { Sigmoid colon. A }\end{array}$ & None & $\mathbf{O}$ & $\begin{array}{l}\text { Cerebral infarct. Recent } \\
\text { investigation for } \\
\text { anaemia: no cause found }\end{array}$ \\
\hline 4 & $82 \mathrm{M}$ & $\begin{array}{l}6 \cdot 0, \text { moderately well-differentiated } \\
\text { adenocarcinoma. } \\
\text { Rectum. B }\end{array}$ & $\begin{array}{l}1 \text { tubular adenoma } \\
0.7 \text {. Transverse colon }\end{array}$ & $\mathrm{O}$ & Myocardial infarct \\
\hline 5 & $82 \mathrm{M}$ & $\begin{array}{l}5 \cdot 0 \text {, well-differentiated adenocarcinoma. } \\
\text { Rectum. C }\end{array}$ & None & $\mathrm{O}$ & $\begin{array}{l}\text { Lobar pneumonia, } \\
\text { diverticulitis of sigmoid } \\
\text { colon }\end{array}$ \\
\hline 6 & $80 \mathrm{~F}$ & $\begin{array}{l}0 \cdot 9 \text {, pedunculated tubular adenoma with } \\
\text { malignant change. } \\
\text { Sigmoid colon. A }\end{array}$ & None & $\mathbf{H}$ & Hypothermia \\
\hline 7 & $88 \mathrm{~F}$ & $\begin{array}{l}\text { (1) } 3 \cdot 5 \text {, well-differentiated adenocarcinoma. } \\
\text { Sigmoid colon. B } \\
\text { (2) } 1 \cdot 8 \times 1 \cdot 0 \text {, poorly-differentiated } \\
\text { adenocarcinoma. } \\
\text { Transverse colon. C }\end{array}$ & $\begin{array}{l}1 \text { tubular adenoma } \\
0 \cdot 6 . \text { Ascending colon }\end{array}$ & $\mathbf{O}$ & $\begin{array}{l}\text { Acute cardiac ischaemia } \\
\text { due to severe coronary } \\
\text { artery atheroslerosis }\end{array}$ \\
\hline 8 & $91 \mathrm{~F}$ & $\begin{array}{l}\text { 3.0, well-differentiated adenocarcinoma. } \\
\text { Descending colon. C }\end{array}$ & $\begin{array}{l}2 \text { tubular adenomas } \\
\text { (1) } 0 \cdot 2 \text {. Transverse colon } \\
\text { (2) } 0 \cdot 3 \text {. Descending colon }\end{array}$ & $\mathrm{O}$ & Bronchopneumonia \\
\hline
\end{tabular}


correlation between a high prevalence rate of hyperplastic polyps and the incidence of colorectal carcinoma, it is widely held that this type of polyp has no malignant potential, a conclusion supported by morphological ${ }^{p 8}$ and epidemiological findings. ${ }^{9}$

The high prevalence of adenomas found in this study is in keeping with other recent series from areas where the incidence of colorectal cancer is high. ${ }^{10-13}$ Both the prevalence of single and multiple adenomas was found to rise with increasing age.

Previous necropsy reports from high incidence areas have given prevalence rates of adenomas ranging from 7 to $51 \%$. The major reason for these differences has been that some of the studies were retrospective and incorporated data based on the observations of a number of prosectors. ${ }^{14}$ It is essential in arriving at a realistic assessment of adenoma prevalence that a prospective study is carried out in which, in individual cases, the whole of the large bowel, including the anorectal junction, is examined.

In order to ascertain any selection bias which might be introduced by considering only those cases where death has occurred in hospital we studied in addition cases from people dying outside hospital. There was no significant difference in prevalence between the two groups.

The adenomas in this series were distributed fairly evenly along the length of the bowel. This does not necessarily mean that all areas of the bowel have an equal propensity to develop adenomas, however, as the surface area of the large intestine at different sites varies. In cases with only a single adenoma present, a disproportionate number occurred in the first 10 and last $20 \%$ of the bowel. Similar findings were obtained by Ekelund ${ }^{15}$ in a necropsy study in Malmö, Sweden, who found $56.1 \%$ of solitary. adenomas in the sigmoid colon and rectum and $18.8 \%$ in the caecum. When those cases in which more than one adenoma is present are considered this site predilection appears to be diluted, so that a more even distribution is apparent.

In two previous series ${ }^{12} 14$ a shift in the distribution of adenomas to the right side of the colon was observed in older age groups, a finding of some interest in that some recent reports show an increase in the incidence of adenocarcinoma of the ascending colon in the elderly. ${ }^{16-18}$ In this series no variation in the distribution of adenomas at different ages was apparent.

The more even distribution of adenomas in the large bowel compared with carcinomas has been put forward by some as evidence against adenomas being premalignant lesions. ${ }^{19}$ It has been shown, however, from pathological study of surgical series of adenomas that malignant potential increases with increasing size, increasing degrees of dysplasia of the epithelium, and a villous as opposed to a tubular type of growth pattern. ${ }^{20}$ These factors are to some extent interrelated, in that larger adenomas tend to have a villous growth pattern and to show more severe degrees of epithelial atypia. The assessment of epithelial atypia and the type of growth pattern is subjective and affected by sampling. ${ }^{21}$ In addition in necropsy material autolysis can interfere with interpretation of cytological detail, although studies have been carried out where dysplasia was categorised. ${ }^{22}{ }^{23}$ In practice the objective measurement of size is most valuable. With the use of this criterion $87.2 \%$ of adenomas were less than $1 \mathrm{~cm}$ in diameter in our series. It is known that adenomas in this range have a low malignant potential. Thus $1.3 \%$ of such adenomas showed malignant change in the St Mark's Hospital material $;{ }^{20}$ this is probably an overestimate, as surgical series would tend to select for the larger polyps within this size range. In adenomas between 1 and $2 \mathrm{~cm}$ in diameter the malignancy rate rose to approximately $10 \%$.

Adenomas greater than $1 \mathrm{~cm}$ in diameter in our series showed a tendency to occur more frequently in the caecum, sigmoid colon, and rectum than at other sites in the large bowel. Thus the distribution of large adenomas approximates to that of colorectal carcinoma.

There are considerable discrepancies in the location of adenomas when surgical and necropsy series are compared. In earlier series of surgical cases a substantial majority of adenomas removed came from the sigmoid colon and rectum, having been detected at routine sigmoidoscopic examination. ${ }^{24}{ }^{25}$ Colonoscopic series have shown that approximately two-thirds of adenomas occur in the bowel distal to the splenic flexure and one-third proximal to this site,$^{26} 27$ a much better, although not exact, correlation with series studied at necropsy. Colonoscopy, however, is carried out on a selected population, many of whom are examined for rectal bleeding, and this will tend to discriminate for larger and for left-sided lesions. As well as this, the smallest adenomas, which in our study occurred more frequently in the right colon, can be either missed, ignored, or destroyed by the biopsy technique at colonoscopic examination.

If adenomas are precursors of large bowel cancer then their prevalence in different populations should be directly correlated with the incidence of carcinoma. Broadly speaking this appears to be true,${ }^{9}$ but there are discrepancies. This can be seen, for example, by comparing our results with a recent necropsy study from Troms $\varnothing$ in northern Norway ${ }^{12}$ where the same protocol was followed and the age distribution of the cases studied was similar. 
Although the incidence of colorectal cancer is considerably lower in northern Norway than in Liverpool, ${ }^{\not 8}$ a higher prevalence of adenomas was found with an overall rate of $40 \%$ in males and $33 \%$ in females. This could be due to differences in the detection rate of very small polyps or to variations in their histological classification. This explanation appears to be unlikely, however, as fewer adenomas in the size range 5-9 $\mathrm{mm}$ were found in our series compared with that from Norway, even though lesions of this size could not fail to be detected and histological classification is much easier with larger polyps. It can be seen, however (Table 8), that the proportion of adenomas over $1 \mathrm{~cm}$ in diameter is higher in our series than in the Norwegian study. These findings lend support to the hypothesis that the factors which result in the appearance of adenomas in a population differ from those involved in their subsequent growth. ${ }^{29}$

The presence of carcinoma in eight of the 365 cases was unexpected. Three of the nine tumours were confined to the bowel wall (Dukes's ' $A$ ') and in two of these there was histological evidence of origin from an adenoma. In both cases death had taken place in hospital. In the remaining six cases death had occurred outside hospital. One subject had been investigated for anaemia without a cause being found but none of the other five cases had presented to a general practitioner, although in view of the large size of some of the tumours, symptoms and signs of colorectal carcinoma may have been present during life.

Incidentally discovered carcinomas of the large bowel at necropsy tend to occur in the elderly, to include a higher percentage of Dukes's ' $A$ ' cases than surgical series, and to be disproportionately distributed in the proximal colon. ${ }^{13}{ }^{3} 31$ The first two of these criteria, if not the third, were true of this series.

Table 8 Number and proportion of adenomas of different sizes in Troms $\emptyset$ and Liverpool

\begin{tabular}{|c|c|c|c|c|c|c|}
\hline & \multicolumn{6}{|c|}{ Adenomas ( $\mathrm{mm}$ ) } \\
\hline & \multicolumn{2}{|l|}{$<5$} & \multicolumn{2}{|l|}{$5-9$} & \multicolumn{2}{|l|}{$10+$} \\
\hline & (no.) & $(\%)$ & (no.) & $(\%)$ & (no.) & (\%) \\
\hline $\begin{array}{l}\text { Troms } \varnothing \text {, } \\
\text { Norway } \\
\text { Liverpool, }\end{array}$ & 123 & $43 \cdot 9$ & 133 & $47 \cdot 9$ & 24 & $8 \cdot 6$ \\
\hline England & 103 & $42 \cdot 6$ & 108 & $44 \cdot 6$ & 31 & $12 \cdot 8$ \\
\hline
\end{tabular}

This study was supported by a grant from the Mersey Regional Health Authority. We are grateful to Mr Alan Williams for illustrations and to Mrs F Sardiwalla and Miss C Wicks for technical assistance.

\section{References}

1 Day DW, Morson BC. The adenoma-carcinoma sequence. In: Morson $\mathrm{BC}$, ed. The pathogenesis of colorectal cancer. Philadelphia: Saunders, 1978: 58-71.

2 Riddell RH. The percarcinomatous phase of ulcerative colitis. In: Morson BC, ed. Current topics in pathology, vol. 63. Berlin, Heidelberg: Springer-Verlag, 1976: 179-219.

3 Westhues M. Die pathologisch-anatomischen Grundlagen der Chirurgie des Rektumkarzinoms. Leipzig: Thieme, 1934.

4 Arthur JF. Structure and significance of metaplastic nodules in the rectal mucosa. J Clin Pathol 1968; 21: 735-43.

5 Morson BC, Sobin LH. Histological typing of intestinal tumours. Geneva: WHO, 1976.

6 Muto T, Bussey HJR, Morson BC. Pseudocarcinomatous invasion in adenomatous polyps of the colon and rectum. J Clin Pathol 1973; 26: 25-31.

7 Morson BC. Some peculiarities in the histology of intestinal polyps. Dis Colon Rectum 1962; 5: 337-44.

8 Lane N, Kaplan H, Pascal R. Minute adenomatous and hyperplastic polyps of the colon: divergent patterns of epithelial growth with specific associated mesenchymal changes. Gastroenterology 1971; 60: 537-61.

9 Correa P. Epidemiology of polyps and cancer. In: Morson BC, ed. The pathogenesis of colorectal cancer. Philadelphia: Saunders, 1978: 126-52.

10 Stemmermann GN, Yatani R. Diverticulosis and polyps of the large intestine. A necropsy study of Hawaii Japanese. Cancer 1973; 31: 1260-70.

11 Correa P, Strong JP, Reif A, Johnson WD. The epidemiology of colorectal polyps. Prevalence in New Orleans and international comparisons. Cancer 1977; 39: 2258-64.

12 Eide TJ, Stalsberg H. Polyps of the large intestine in northern Norway. Cancer 1978; 42: 2839-48.

13 Rickert RR, Auerbach O, Garfinkel L, Hammond EC, Frasca JM. Adenomatous lesions of the large bowel: an autopsy survey. Cancer 1979; 43: 1847-57.

14 Chapman I. Adenomatous polypi of large intestine: incidence and distribution. Ann Surg 1963; 157: 223-6.

15 Ekelund G. On cancer and polyps of colon and rectum. Acta Pathol Microbiol Scand 1963; 59: 165-70.

16 Haenszel W, Correa P. Cancer of the colon and rectum and adenomatous polyps. A review of epidemiological findings. Cancer 1971; 28: 14-24.

17 de Jong UW, Day NE, Muir CS et al. The distribution of cancer within the large bowel. Int J Cancer 1972; 10: 463-77. 
18 Snyder DN, Heston JF, Meigs JW, Flannery JT. Changes in site distribution of colorectal carcinoma in Connecticut, 1940-1973. Am J Dig Dis 1977; 22: 791-7.

19 Spratt JS, Ackerman LV, Moyer CA. Relationship of polyps of the colon to colonic cancer. Ann Surg 1958; 148: $682-96$.

20 Muto T, Bussey HJR, Morson BC. The evolution of cancer of the colon and rectum. Cancer 1975; 36: 2251-70.

21 Fung CHK, Goldman $H$. The incidence and significance of villous change in adenomatous polyps. Am J Clin Pathol 1970; 53: 21-5.

22 Sato E, Ouchi A, Sasano N, Ishidate T. Polyps and diverticulosis of large bowel in autopsy population of Akita prefecture compared with Miyagi. High risk for colorectal cancer in Japan. Cancer 1976; 37: 1316-21.

23 Cuello C, Marigo C, Correa P. Atypia in adenomas in three populations with different risk for large bowel cancer: Cali, Sao Paulo, and New Orleans. Second Symposium on Epidemiology and Cancer Registries in the Pacific Basin, Bethesda, Maryland: National Institutes of Health 1979: 171-3.

24 Grinnell RS, Lane N. Benign and malignant adenomatous polyps and papillary adenomas of the colon and rectum. An analysis of 1856 tumors in 1335 patients. Int Abstr Surg 1958; 106: 519-38.

25 Enterline HT, Evans GW, Mercado-Lugo R, Miller L, Fitts WT Jr. Malignant potential of adenomas of colon and rectum. JAMA 1962; 179: 322-30.

26 Gillespie PE, Chambers TJ, Chan KW, Doronzo F, Morson BC, Williams CB. Colonic adenomas - a colonoscopy survey. Gut 1979; 20: 240-5.

27 Tedesco FJ, Waye JD, Avella JR, Villalobos MM. Diagnostic implications of the spatial distribution of colonic mass lesions (polyps and cancers). A prospective colonoscopic study. Gastrointest Endosc 1980; 26: 95-7.

28 Waterhouse J, Muir C, Correa P, Powell J. Cancer incidence in five continents, vol 3. Lyon: IARC, 1976.

29 Hill MJ, Morson BC, Bussey HJR. Aetiology of adenoma-carcinoma sequence in large bowel. Lancet 1978; 1: 245-7.

30 Stemmermann GN. Cancer of the colon and rectum discovered at autopsy in Hawaiian Japanese. Cancer 1966; 19: 1567-72.

31 Berg JW, Downing A, Lukes RJ. Prevalence of undiagnosed cancer of the large bowel found at autopsy in different races. Cancer 1970; 25: 1076-80. 